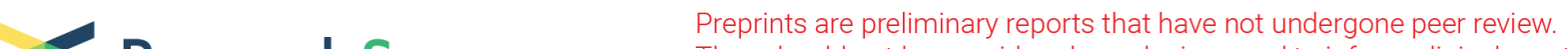 $\begin{array}{ll}\text { Research Square } & \text { They should not be considered conclusive, used to inform clinical practice, } \\ \text { or referenced by the media as validated information. }\end{array}$
}

\section{Modulating Inherent Lewis Acidity at the Intergrowth Interface of Mortise-Tenon Zeolite Catalyst}

\section{Huiqiu Wang}

Beijing Key Laboratory of Green Chemical Reaction Engineering and Technology Department of Chemical Engineering Tsinghua University https://orcid.org/0000-0002-3707-5095

\section{Boyuan Shen}

Beijing Key Laboratory of Green Chemical Reaction Engineering and Technology Department of Chemical Engineering Tsinghua University

\section{Xiao Chen}

Tsinghua University https://orcid.org/0000-0003-1104-6146

\section{Hao Xiong}

Tsinghua University https://orcid.org/0000-0001-5479-7754

\section{Hongmei Wang}

Tsinghua University

\section{Wenlong Song}

Tsinghua University

\section{Chaojie Cui}

Tsinghua University

\section{Fei Wei}

Tsinghua University https://orcid.org/0000-0002-1422-9784

Wei-Zhong Qian ( $\nabla$ qianwz@tsinghua.edu.cn )

Tsinghua University https://orcid.org/0000-0002-1684-1061

\section{Article}

Keywords: Tunability of Local Structures, Methanol Conversion, Lattice Mismatch, Scanning Transmission Electron Microscope, Tailored Catalytic Functions, Interface Engineering

Posted Date: May 19th, 2021

DOI: https://doi.org/10.21203/rs.3.rs-368783/v1

License: (c) (i) This work is licensed under a Creative Commons Attribution 4.0 International License. Read Full License 
Version of Record: A version of this preprint was published at Nature Communications on May 25th, 2022. See the published version at https://doi.org/10.1038/s41467-022-30538-7. 


\section{Abstract}

The tunability of local structures determines various catalytic performances of zeolite catalysts. The acid sites in zeolite catalysts are important local structures to control the products in methanol conversion. However, it remained still a great challenge to precisely design the acid sites, since there is a lack of controllable methods to generate and identify the acid sites with a high resolution. Here, we use the lattice mismatch of zeolite intergrowth to enrich the inherent Lewis acid sites (LASs) at the interface of a mortise-tenon ZSM-5 catalyst (ZSM-5-MT) showing a $90^{\circ}$ intergrowth structure. ZSM-5-MT is formed by two perpendicular blocks that can be atomically resolved by the integrated differential phase contrast scanning transmission electron microscope (iDPC-STEM). It can be revealed by various methods that more framework-associated Al ( $\mathrm{Al}_{\mathrm{FR}}$ ) LASs are generated in ZSM-5-MT than single-crystal ZSM-5 catalyst. Combining with the iDPC-STEM results, we demonstrate that the partial missing of 0 atoms at interfaces results in the formation of inherent LASs in ZSM-5-MT. According to the catalytic performances, LAS-enriched ZSM-5-MT shows a higher selectivity of light olefins than the single-crystal ZSM-5 catalyst in methanol conversion. These results provide an efficient strategy to design the Lewis acidity in zeolites for tailored catalytic functions via interface engineering.

\section{Introduction}

Zeolite is a class of typical crystalline microporous materials consisting of $\mathrm{TO}_{4}(\mathrm{~T}=\mathrm{Si}, \mathrm{Al}, \mathrm{P})$ tetrahedra framework. Aluminosilicate zeolites can be used as important solid acid catalysts in a wide range of catalytic applications due to active Brønsted acid sites (BASs) and Lewis acid sites (LASs) ${ }^{1,2}$. Methanol to hydrocarbons (MTH) conversion is one of the most important applications of zeolite catalysts. Based on the hydrocarbon pool (HP) mechanism, different products can be obtained during an olefins-based circle and an aromatics-based cycle running in $\mathrm{HP}^{3-5}$, affected by the tunable acidic sites(density, type and distribution) and pore structure. Besides the common BASs, LASs also strongly affect the production of light olefins and aromatics. For example, Lewis acidic $\left[\mathrm{M}(\mu-\mathrm{OH})_{2} \mathrm{M}\right]^{2+}(\mathrm{M}=\mathrm{Ca}, \mathrm{Mg}$, and $\mathrm{Sr})$ species formed by incorporating alkaline-earth metals in zeolite catalysts will increase the benzene methylation barriers and destabilize typical cyclic carbocations in aromatics-based cycle for higher a propylene selectivity ${ }^{6,7}$. Modulating Lewis acidity in zeolites efficiently adjust the contribution of two cycles to obtain target products, since the catalytically active acid sites in zeolites play a tangible role in determining local concentrations and activities of hydrocarbon species ${ }^{3,6-10}$. Al LASs can be constructed in zeolites with near all kinds of zeolite topologies, which are classified into extra-framework $\mathrm{Al}\left(\mathrm{Al} \mathrm{EF}_{\mathrm{EF}}\right)$ and inherent $A I_{F R}$ LASs based on their distinct structures ${ }^{11,12}$. The $A l_{E F}$ LASs can be generated by removing $A l$ atoms from zeolite frameworks in post treatments, including steaming and acid or base leaching ${ }^{13-16}$. However, the controllable synthesis of $\mathrm{Al}_{\mathrm{FR}}$ LASs has not been achieved to date. Here, we propose that the mismatch at the interface of zeolite intergrowths will cause the missing of $O$ atoms and generate the inherent $\mathrm{Al}_{\mathrm{FR}}$ LASs. And interface engineering still works in porous materials to tailor the catalytic performances by designing additional Lewis acidity. 
ZSM-5 is a MFI-type zeolite with cross-linked straight and sinusoidal channels, which has been well studied for MTH catalysis ${ }^{17-21}$. ZSM- 5 crystals, as contacted, can form $90^{\circ}$ intergrowth by connecting straight and sinusoidal channels ${ }^{22-26}$. Such intergrowths will theoretically generate a large number of $\mathrm{Al}$ LASs at the junctions of different types of channels. However, there is still a lack of atomic information on zeolite interface, owing to the uneasy availability of perfect crystal samples with atomic scale order and the constrainment of imaging including the sensitivity of zeolite structure to the electron beams and low contrasts of light elements with (scanning) transmission electron microscope ((S)TEM) ${ }^{27-30}$. Recently, the progress of integrated differential phase contrast (iDPC) STEM techniques allowed us achieve the low-dose imaging of various light-element beam-sensitive materials with ultra-high resolution,

such as zeolites and metal-organic frameworks ${ }^{31,32}$. Thus, it can be expected that the iDPC-STEM can be used to resolve the atomic structures of intergrowth interfaces in ZSM-5 frameworks, providing deep understandings on the Lewis acidity at zeolite interfaces.

In this work, we create a $\mathrm{Al}_{\mathrm{FR}}$-LAS-enriched interface in a mortise-tenon ZSM-5 catalyst (ZSM-5-MT) with $90^{\circ}$ intergrowth structures with high crystallinity. Using the iDPC-STEM, we can resolve the atomic interface structure in ZSM- 5 intergrowth, and we obviously find the missing of $O$ atoms at this interface which may contribute to the formation of $\mathrm{Al}_{\mathrm{FR}}$ LASs. Then, we reveal the enrichment of $\mathrm{Al}_{\mathrm{FR}}$ LASs in ZSM5 -MT by different methods, including the ${ }^{27} \mathrm{Al}$ solid state nuclear magnetic resonance (NMR) and Fourier transform infrared (FTIR) spectroscopy of adsorbed probe molecules (carbon monoxide and pyridine). The catalytic results show that the ZSM-5-MT can significantly improve the selectivity of light olefins in the MTH catalysis compared with traditional ZSM- 5 catalysts. These results bridge the gap between the local structure and catalytic performance of $\mathrm{Al}_{\mathrm{FR}} \mathrm{LASs}$ at intergrowth interfaces, providing an efficient strategy for the further design of Lewis acidity.

\section{Results}

\section{Morphology of ZSM-5-MT catalyst}

ZSM-5-MT catalyst was synthesized via a one-pot hydrothermal process (as shown in Methods). The three-dimensional (3D) morphology of ZSM-5-MT catalyst is revealed by the 3D electron tomographic reconstruction in Fig 1a and Supplementary Video 1. In such ZSM-5-MT, a tenon-like protrusion vertically grows on the (010) surface of a underlying ZSM- 5 crystal as a mortise subunit (as shown in the schematic model Fig. 1b). The morphology of ZSM-5-MT can also be confirmed by the annular dark field (ADF) STEM images (Fig. 1c-e) and the SEM images (Supplementary Fig.1) of various 2D projections. In the X-ray diffraction (XRD) results in Supplementary Fig.2, we only detect the pure MFI zeolite phase in both ZSM-5-MT and traditional short-b-axis ZSM-5 (ZSM-5-Sb) ${ }^{33-35}$. Thus, the mortise-tenon morphology should be caused only by the intergrowth of ZSM- 5 lattices. Consistent pore structures of ZSM-5-MT and ZSM-5-Sb are confirmed by the gas physisorption experiments. As shown in Supplementary Fig. 3 and table 1, there is no evidence that additional mesopores are introduced in ZSM-5-MT, indicating that the tenon and mortise subunits are closely connected without any gaps. 
Then, we used the iDPC-STEM to identify local structures and study such intergrowth behavior in detail. In the iDPC-STEM image obtained from the purple frame in Fig. 1d, we can observe three different areas according to different projected structures as shown in Fig. $1 \mathrm{f}$. In this projection, the pure tenon area shows the typical (010) surface with the ordered 10-membered rings of straight channels, while the pure mortise area shows the (100) surface with the sinusoidal channels. It indicates that the crystallographic axes $\mathbf{a}$ and $\mathbf{b}$ are rotated by $90^{\circ}$ around $\mathbf{c}$ in space to form the tenon and mortise respectively. Meanwhile, in the intergrowth area in Fig. 1f, we find the overlapping contrast of (010) and (100) lattice planes where the straight channels are blurred by the perpendicular lattices above. It means that the mortise and tenon subunits grow into each other in a perpendicular intergrowth structure just like the structure of a traditional mortise-tenon junction.

We also investigated the connection of channels in tenon and mortise using the images with different defocuses. Fig. $1 \mathrm{~g}$ and $\mathrm{h}$ are obtained from the same area marked by the red frame in Fig. $1 \mathrm{e}$ but with different defocuses. In Fig 1g, the (100) surface of mortise subunit is in focus and the sinusoidal channels are clearly imaged in accordance with the structural model. While, in Fig. 1 h, the (010) surface of tenon subunit with straight channels is in focus after changing the defocus. Combining with the imaged structures in Fig $1 \mathrm{~g}$ and $\mathrm{h}$, it can be deduced that the straight channels in mortise and the sinusoidal channels in tenon are perfectly connected without any dislocations and regardless of local lattice mismatching. We can also confirm such channel connectivity from another projection where the (010) surface of mortise subunit and the (100) surface of tenon subunit can be imaged with different defocuses. As marked by the red hexagons in Fig $1 \mathrm{i}$ and $\mathrm{j}$, the projected positions of the channels in mortise and tenon are coherently located. Moreover, we also revealed other local structures in the ZSM-5MT, including surface terminations, surface steps and step-edge sites (Supplementary Fig. 4). These results provide an overall understanding on the morphology of ZSM-5-MT and reveal such intergrowth behavior with confirmed channel connectivity preliminarily.

\section{Resolving the atomic interface structures of ZSM-5-MT catalyst}

Atomic structures of intergrowth interfaces can be investigated by the imaging from the [001] direction of ZSM-5-MT. In this projection (Fig. 2a), it is possible to observe the interfaces to reveal how two areas with different lattice orientations (tenon and mortise) grow into each other. Fig. $2 b$ is the iDPC-STEM image obtained from the blue area in Fig. 2a, which clearly shows the lattice characteristics in this projection. Fig. 2c gives two structural models with a $90^{\circ}$ rotation in the [001] projection, where the straight and sinusoidal channels are marked out. The green arrows in Fig. $2 c$ show a characteristic pattern (projected Si-O island), which helps us to identify the lattice orientations. Such characteristic patterns can be observed from the iDPC-STEM and simulation (Fig. 2d). Then, at the intergrowth area, these rotating lattices with two orientations will overlap. If the characteristic arrows in upper and lower lattices are the same, the characteristic patterns are retained in the overlapped image. If not, a square pattern appears in the overlapped image instead. These results are shown in the image, simulation and model in Fig. 2e-g. Based on our analysis on image characteristics, we can identify two areas with different lattice orientations (tenon and mortise) according to the green arrows in Fig. 2b. Meanwhile, we can also use the 
red frames to outline an intergrowth area that contains the interfaces between the tenon and mortise subunits, where the image is just the overlap of the lattice images in two subunits growing into each other.

Furthermore, we resolved such interface structures in detail. In the [001] projection, we can observe not only the characteristic patterns but also the contrast of $\mathrm{O}$ atoms between them. Based on the structural model in Fig. $2 \mathrm{~h}$, there is an inherent missing of $\mathrm{O}$ atoms at the interface between the $90^{\circ}$-rotation lattices. In order to study such atom missing, we used the profile analysis of IDPC-STEM images to give the positions and intensities of $O$ peaks as shown in Fig. 2i. The normalized intensities of $O$ peaks can describe the different numbers of atoms in these 0 atom columns semi-quantitatively. We have made statistics on the intensities of these 0 atom columns in single-crystal (tenon or mortise) and intergrowth areas respectively according to the profile data in Supplementary Fig. 6-9. As shown in Fig. 2j, the statistical intensities are all higher than 0.6 for the single-crystal area, while the results for the intergrowth area are varying in a wide range (0.2-1). It indicates the obvious missing of 0 atoms at the interface in this intergrowth area. This can be interpreted that the increasing distances between Si or Al atoms due to the lattice mismatch at the interface make them impossible to be bonded by 0 atoms. These results reveal the interface structures of tenon-mortise intergrowth in atomic precision, and the non-tetracoordinated $\mathrm{Al}$ atoms formed by the missing of $\mathrm{O}$ atoms will generate more Lewis acidity to improve the performances of ZSM-5-MT catalyst.

\section{Inherent Lewis acidity in ZSM-5-MT catalyst}

In order to establish the structure-property relation of ZSM-5-MT catalyst, we studied the inherent Lewis acidity in ZSM-5-MT compared with traditional ZSM-5-Sb without intergrowth. First, the acid property was investigated by the temperature-programmed $\mathrm{NH}_{3}$ desorption $\left(\mathrm{NH}_{3}\right.$-TPD) in Supplementary Fig. 10. The $\mathrm{NH}_{3}$-TPD results show that the peaks of both weak and strong acid sites in ZSM-5-MT shift to higher temperatures than those in ZSM-5-Sb, which demonstrates an unusual change in the acid properties of ZSM-5-MT. Then, the acid sites in ZSM- 5 zeolites are detected by Fourier transform infrared (FTIR) spectroscopy of adsorbed pyridines and carbon monoxides (CO). These two different probe molecules were used together for a deeper knowledge on the nature of acid sites. The FTIR spectra using pyridines as probe molecules are shown in Fig 3a. The bands at 1430-1470 cm-1 and $1544 \mathrm{~cm}^{-1}$ can be ascribed to coordinately bond pyridines (pyridines interacting with LASs) and pyridinium ions (pyridines interacting with BASs) respectively ${ }^{15,36,37}$. As we summarized in Supplementary Table 2, the concentration of BAS in ZSM-5-MT is nearly equal to that in ZSM-5-Sb, while the concentration of LAS in ZSM-5-MT is one-order of magnitude higher than that in ZSM-5-Sb. Meanwhile, the signal of LAS in ZSM-5-MT is slightly blue shifted $\left(\sim 17 \mathrm{~cm}^{-1}\right)$ with regard to the signal in ZSM-5-Sb, which implies the formation of additional acid sites with Lewis acidity in ZSM-5-MT.

To finely distinguish between multiple LASs, we further detected these acid sites using $\mathrm{CO}$ as probe molecules for the FTIR spectroscopy (Fig. 3b). The peak at $2129 \mathrm{~cm}^{-1}$ indicates the physisorbed $\mathrm{CO}$ and the peak at $2168 \mathrm{~cm}^{-1}$ results from the CO interacting with the BASs in zeolites ${ }^{38}$. Interestingly, the ZSM-5- 
MT shows two bands at $2338 \mathrm{~cm}^{-1}$ and $2358 \mathrm{~cm}^{-1}$, which are attributed to the CO interactions with penta-coordinated and tri-coordinated LASs respectively after the dehydration of zeolites during sample pretreatment (Fig.3c), while the ZSM-5-Sb does not. Such Al-CO interactions can be promoted by the decoordination of water from the octahedral Al sites. Combining with the iDPC-STEM imaging results, it can be concluded that these penta-coordinated and tri-coordinated LASs are closely related to the inherent missing of $\mathrm{O}$ atoms at the tenon-mortise interfaces, which fully agrees with our prediction on Lewis acidity.

To verify Al sites in terms of their coordination, ${ }^{27} \mathrm{Al}$ magical-angle-spinning (MAS) nuclear magnetic resonance (NMR) was performed under ambient conditions without pre-treatment (dehydration). The ${ }^{27} \mathrm{Al}$ MAS NMR spectra (Fig. 4d) of both ZSM-5-MT and ZSM-5-Sb show sharp peaks at 58 ppm that are attributed to tetra-coordinated Al in bulk framework. It validates that most of Al atoms are incorporated into framework. Meanwhile, the ZSM-5-Sb shows a broad peak of chemical shift at $0 \mathrm{ppm}$ belongs to distorted octahedral Al species. As for the ZSM-5-MT, this peak is higher than that for the ZSM-5-Sb and shifts to 4 ppm corresponding to the boehmite-like structures (given in Supplementary Fig. 11) ${ }^{39}$. It can be deduced that such boehmite-like structures only exist when the high-density LASs are very close in space to connect, for example, when the LASs are concentrated at the interface of zeolite intergrowth. Based on the FTIR and ${ }^{27} \mathrm{Al}$ MAS NMR results, the inherent LASs caused by the missing of $O$ atoms in ZSM-5-MT are confirmed experimentally, which is also consistent with the imaging results above.

\section{Catalytic performances of ZSM-5-MT catalyst}

To address the effect of these $\mathrm{Al}_{\mathrm{FR}}$ Lewis acid sites, we tested the catalytic performances of ZSM-5-MT and ZSM-5-Sb catalysts in methanol conversion at high conversion rate $(\geq 99 \%)$. The gas product selectivities are given in Fig. 4a-b and Supplementary Fig.12, which indicates that two catalysts with different architectures exhibit quite different catalytic performances. The selectivities of propylene (25$29 \%$ ) and butene (12-13\%) over ZSM-5-MT are higher than those over ZSM-5-Sb (18-19\% and 11\%, respectively). Meanwhile, the ZSM-5-MT shows lower selectivities of $\mathrm{C}_{1}-\mathrm{C}_{5}$ alkanes (32-38\%) and aromatics $(\sim 8 \%)$ than the ZSM-5-Sb (42-44\% and 12\%, respectively). It is known in the hydrocarbon pool (HP) mechanism that the aromatics-based cycle produces almost equal amounts of ethylene and propylene, while the olefins-based cycle will produce much more propylene than ethylene ${ }^{40-42}$. Therefore, the relative contribution of two cycles can be represented by the ratio of ([propylene]-[ethylene])/[ethylene] $((P-E) / E)$. As shown in Fig. 4a and b, the descriptor (P-E)/E ratio of ZSM-5-MT is much higher than that of ZSM-5-Sb, implying that the olefins-based cycle is more significantly enhanced in ZSM-5-MT. And, another criterion for determining the relative contribution of two cycles is the hydrogen transfer index $(\mathrm{HTI})^{10}$. As shown in Supplementary Fig. 13 , the $\mathrm{C}_{4}-\mathrm{HTI}$ and $\mathrm{C}_{5}-\mathrm{HTI}$ of ZSM-5-MT are lower than those of ZSM-5-Sb, indicating the less vigorous hydrogen transfer reactions in ZSM-5-MT. Thus, both of these two criteria demonstrate that the enhanced olefins-based cycle is induced in ZSM-5-MT. To explicitly illustrate the hydrogen transfer $(\mathrm{HT})$ capacity, we further evaluated the catalytic performances of ZSM-5-MT and ZSM-5-Sb catalysts in propylene conversion (Fig. 4c). The ZSM-5-MT catalyst shows lower selectivities of 
both propane $(\sim 16 \%)$ and butane $(\sim 6 \%)$, which are the predominant HT products in propylene conversion, than the ZSM-5-Sb catalyst ( $22 \%$ and $\sim 7 \%$ respectively). This comparison reveals that the introduction of $\mathrm{Al}_{\mathrm{FR}}-\mathrm{LAS}$-enriched interface in a mortise-tenon ZSM-5 catalyst significantly inhibit the olefin-induced hydrogen transfer reaction, thus resulting in a higher propylene selectivity in methanol conversion. Overall, we validated that the modulation of $\mathrm{Al}_{\mathrm{FR}} \mathrm{LASs}$ via interface engineering can be used to design efficient methanol-to-olefins catalysts.

\section{Conclusion}

In summary, we successfully modulated the Lewis acidity in zeolite catalyst by creating mismatched interface in intergrowth structures. In a mortise-tenon ZSM-5 intergrowth, the lattice mismatch on interface will generate the missing of $O$ atoms to form inherent $\mathrm{Al}_{\mathrm{FR}}$ LASs. Using the iDPC-STEM, we can atomically resolve these local structures in real space to confirm the missing of $O$ atoms on interface. Then, we characterized these abundant $\mathrm{Al}_{\mathrm{FR}}$ LASs in ZSM-5-MT by different macroscopic methods, including ${ }^{27}$ AI MAS NMR and FTIR spectroscopy of adsorbed probe molecules. Combining these methods, we find that the tri-coordinated $\mathrm{Al}$ sites caused by the missing of $\mathrm{O}$ atoms contribute to the generation of $\mathrm{Al}_{\mathrm{FR}}$ LASs in ZSM-5-MT. Based on the catalytic test, the resulting $\mathrm{Al}_{\mathrm{FR}}$ LASs in ZSM-5-MT catalysts significantly enhance the olefins-based cycle through the suppression of the olefin-induced hydrogen transfer reaction, thus inducing a higher propylene selectivity in MTH. These results provide a general method of interface engineering to design the zeolite structures for enhanced Lewis acidity, and bring new insights into the structure-property relation of zeolite catalysts from the perspectives on atomic local structures.

\section{Methods}

Synthesis of ZSM-5-MT and ZSM-5-Sb crystals.

ZSM-5-MT and ZSM-5-Sb were both synthesized by a conventional hydrothermal method. Tetraethyl orthosilicate (TEOS), $\mathrm{Al}\left(\mathrm{NO}_{3}\right)_{3} \cdot 9 \mathrm{H}_{2} \mathrm{O}$ and tetrapropylammonium hydroxide (TPAOH) were used as the silicon source, aluminum source and structure-directing agent, respectively. In a typical run of the preparation of ZSM-5-Sb samples, $26.2 \mathrm{~g}$ TPAOH (wt 25\%), $22.4 \mathrm{~g}$ TEOS, $4.0 \mathrm{~g}$ urea, $0.6 \mathrm{~g} \mathrm{Al}\left(\mathrm{NO}_{3}\right)_{3} \cdot 9 \mathrm{H}_{2} \mathrm{O}$, $0.2 \mathrm{~g} \mathrm{NaOH}$ and $0.2 \mathrm{~g}$ iso-propanol (IPA) were added into $36.8 \mathrm{~g} \mathrm{H}_{2} \mathrm{O}$ under stirring. After being stirred for $2 \mathrm{~h}$ at room temperature, the gel was transferred into a $200 \mathrm{~mL}$ stainless steel autoclave with a Teflon liner. The gel was heated from $30{ }^{\circ} \mathrm{C}$ to $180^{\circ} \mathrm{C}$ at a rate of $6.25^{\circ} \mathrm{C} / \mathrm{h}$, and then held for 2 days at $180{ }^{\circ} \mathrm{C}$. Subsequently, the autoclave was quenched with cold water. The solids were filtered, washed three times with deionized water, dried at $110^{\circ} \mathrm{C}$ in air, then calcined at $550{ }^{\circ} \mathrm{C}$ for $6 \mathrm{~h}$ to remove the organic templates.

For the synthesis of ZSM-5-MT samples, $26.2 \mathrm{~g}$ TPAOH (wt 25\%), $22.4 \mathrm{~g}$ TEOS, $4.0 \mathrm{~g}$ urea, $0.6 \mathrm{~g}$ $\mathrm{Al}\left(\mathrm{NO}_{3}\right)_{3} \cdot 9 \mathrm{H}_{2} \mathrm{O}, 0.6 \mathrm{~g} \mathrm{NaOH}$ and $0.2 \mathrm{~g}$ iso-propanol (IPA) were added into $36.8 \mathrm{~g} \mathrm{H}_{2} \mathrm{O}$ under stirring. After 
being stirred for $2 \mathrm{~h}$ at room temperature, the gel was transferred into a $200 \mathrm{~mL}$ stainless steel autoclave with a Teflon liner. The gel was heated from $30{ }^{\circ} \mathrm{C}$ to $180{ }^{\circ} \mathrm{C}$ at a rate of $3.125{ }^{\circ} \mathrm{C} / \mathrm{h}$, and then held for 2 days at $180^{\circ} \mathrm{C}$. The product was extracted from mother liquor using the procedure described above.

In addition, all the Na-type samples were converted into the $\mathrm{H}$-type samples by three-time ion exchanges with $1 \mathrm{M} \mathrm{NH}_{4} \mathrm{NO}_{3}$ solution and subsequent calcination in air at $550{ }^{\circ} \mathrm{C}$ for $5 \mathrm{~h}$.

Imaging conditions and electron tomography experiments.

The high-resolution iDPC-STEM and ADF-STEM images were obtained under a Cs-corrected STEM (FEI Titan Cubed Themis G2 300) operated at $300 \mathrm{kV}$. The STEM was equipped with a DCOR+ spherical aberration corrector for the electron probe which was aligned using a standard gold sample before observations. The aberration coefficients we used were shown as following: $A 1=0.982 \mathrm{~nm} ; A 2=5.79 \mathrm{~nm}$; $\mathrm{B} 2=20.4 \mathrm{~nm} ; \mathrm{C} 3=-250 \mathrm{~nm} ; \mathrm{A} 3=137 \mathrm{~nm} ; \mathrm{S} 3=89.3 \mathrm{~nm} ; \mathrm{A} 4=3.4 \mu \mathrm{m}, \mathrm{D} 4=2.25 \mu \mathrm{m}, \mathrm{B} 4=1.81 \mu \mathrm{m}, \mathrm{C} 5=77.4 \mu \mathrm{m}$, $A 5=175 \mu \mathrm{m}, \mathrm{S} 5=118 \mu \mathrm{m}$, and R5=5.78 $\mu \mathrm{m}$. The convergence semi-angle was $15 \mathrm{mrad}$. And four images used for 2D integration were acquired by a 4-quadrant DF4 detector with an optional high-pass filter applied to reduce the low frequency information in the image. The beam current was reduced lower than $0.1 \mathrm{pA}$. The collection angles of iDPC-STEM imaging were set as 4-22 mrad. The electron tomography experiments were performed using a Fischione 2020 advanced tomography holder aided with Tomography STEM software (Thermo Fisher Scientific). Tilt images were obtained at the range of $\pm 60^{\circ}$ with interval of $2^{\circ}$ at low tilt $\left(-52^{\circ}\right.$ to $\left.50^{\circ}\right)$ and $1^{\circ}$ at high tilt. The commercial Inspect3D software (Thermo Fisher Scientific) was used for 3D tomographic reconstruction. The projected electrostatic potentials were simulated by the QSTEM software (http://www.qstem.org) based on the multislice method and the parameters were identical with those of experiments.

Other characterizations.

The scanning electron microscope of samples were collected using JEOL JSM-7401. Textural analysis of zeolite samples was performed by Ar adsorption/desorption using a Micromeritics ASAP 2460 gas sorptiometer and $\mathrm{N}_{2}$ adsorption/desorption using an Autosorb-iQ2-C system (Quantachrome Instruments). By using the t-plot method, the micropore surface area of samples was determined from $\mathrm{Ar}$ adsorption isotherm. Moreover, micropore volume and micropore size were determined from the adsorption branches of Ar isotherms with relative pressure $\mathrm{p} / \mathrm{p} 0$ of $<0.01$. The Brunauer-Emmett-Teller method was used to determine mesopore surface area from $\mathrm{N}_{2}$ adsorption isotherms. X-ray diffractions (XRD) were recorded on a Rigaku D/Max-RB diffractometer with Cu Ka Radiation at $40 \mathrm{kV}$ and $120 \mathrm{~mA}$ to verify the crystalline structure. ${ }^{27} \mathrm{Al}$ MAS NMR experiments were performed on a JNM-ECZ600R spectrometer at resonance frequencies of $156.4 \mathrm{MHz}$. One-dimensional single-pulse ${ }^{27} \mathrm{Al}$ MAS NMR spectra were collected on a $3.2 \mathrm{~mm}$ probe with a spinning rate of $12 \mathrm{kHz}$. Al $\left(\mathrm{NO}_{3}\right)_{3}$ was used as the reference of chemical shift at $0 \mathrm{ppm}$. The Si/Al ratio of the samples were analyzed by inductively coupled plasma optical emission spectrometer (ICP-OES, SPECTRO ARCOS). $\mathrm{NH}_{3}$ temperature-programmed desorption (TPD) experiments were completed in a Quantachrome automated chemisorption analyzer. 
FTIR spectroscopy.

The low temperature IR spectra of CO adsorbed over zeolites were recorded using a Thermo Nicolet iS20 FTIR spectrometer equipped with $\mathrm{KBr}$ windows, a MCT-A detector and HARRICK in situ reaction chamber. Prior to the measurements, the sample $(200 \mathrm{mg})$ was loaded into the in situ reaction chamber and pretreated in a flow $(25 \mathrm{~mL} / \mathrm{min})$ of $\mathrm{N}_{2}$ at $450{ }^{\circ} \mathrm{C}$ for 1 hour. Then, the chamber was cooled to $-95^{\circ} \mathrm{C}$ for carbon monoxide adsorption measurements. The background spectrum was collected in the continuous $\mathrm{N}_{2}$ flowing. Subsequently, a mixture gas of $1 \mathrm{vol} \% \mathrm{CO} / \mathrm{N}_{2}(25 \mathrm{~mL} / \mathrm{min})$ was introduced into the reaction chamber, and the spectra were collected with time until there was no change in the signals.

The IR spectra of pyridine adsorbed over zeolites were recorded using a Thermo Nicolet iS50 FTIR spectrometer equipped with a DTGS detector and $\mathrm{KBr}$ windows. About $100 \mathrm{mg}$ of the sample was pressed into a self-supporting wafer and activated in in vacuum $\left(<10^{-4} \mathrm{~Pa}\right)$ at $500^{\circ} \mathrm{C}$ for $1 \mathrm{~h}$. For pyridine adsorption, the samples were exposed to pyridine for $1 \mathrm{~h}$ after cooling to $100^{\circ} \mathrm{C}$, then the IR transmission cell was evacuated to vacuum (about $10^{-4} \mathrm{~Pa}$ ). The spectra were collected at $200^{\circ} \mathrm{C}$. For the quantitative comparison, the concentration of Brønsted and Lewis acid sites was calculated based on the IR band area at $1515-1565 \mathrm{~cm}^{-1}$ and $1430-1470 \mathrm{~cm}^{-1}$ after evacuation at $200{ }^{\circ} \mathrm{C}$, using the molar integral extinction coefficients of $1.88 \mathrm{~cm} / \mu \mathrm{mol}$ Brønsted acid sites and $1.42 \mathrm{~cm} / \mu \mathrm{mol}$ for Lewis acid sites.

Catalytic performance tests.

The methanol-to-hydrocarbon (MTH) reaction was performed using a quartz fixed-bed continuous-flow reactor (inner diameter $=10 \mathrm{~mm}$ ) equipped with gas chromatography (GC-2014, equipped with two flame ionization detectors (FIDs) and a thermal conductivity detector (TCD), Shimadzu Co.), catalyst ( $0.3 \mathrm{~g} \mathrm{H}-$ form zeolite, homogeneously diluted with $1 \mathrm{~g}$ of quartz sand) and a reaction temperature of $475{ }^{\circ} \mathrm{C}$. $\mathrm{CH}_{3} \mathrm{OH}$ (99.9\% purity) was continuously pumped into the reactor at a WHSV of $5 \mathrm{~h}$ by a plunger pump (Labaliance Series $\otimes$ ) at $0.03 \mathrm{~mL} / \mathrm{min}$ with a preheat inert gas of nitrogen $(15 \mathrm{~mL} / \mathrm{min})$. The effluent from the reactor was maintained at $200^{\circ} \mathrm{C}$ and analyzed online by a gas chromatography. All the data discussed in article was collected after 5 hours of MTH reaction.

The propylene conversion reaction was carried out in an identical quartz fixed-bed continuous-flow reactor and at $450{ }^{\circ} \mathrm{C}$. Typically, $0.5 \mathrm{~g} \mathrm{H}$-form zeolite diluted with $2.5 \mathrm{~g}$ of quartz sand was loaded. Both propylene and inert nitrogen were fed in at a flow rate of $15 \mathrm{~mL} / \mathrm{min}$.

\section{Data availability}

The authors declare that all relevant data supporting the findings of this study are available within the paper and its Supplementary Information files. Additional data are available from the corresponding authors upon reasonable request.

\section{Declarations}


Acknowledgments

This work was supported by the National Key Research and Development Program of Ministry of Science and Technology (No. 2020YFB0606401), the National Key Research and Development Program of China (2018YFB0604801), and the National Natural Science Foundation of China (22005170).

\section{Competing interests}

The authors declare no competing interests.

\section{References}

1. Corma A. From Microporous to Mesoporous Molecular Sieve Materials and Their Use in Catalysis. Chem. Rev. 97, 2373-2420 (1997).

2. Bhan A, Iglesia E. A Link between Reactivity and Local Structure in Acid Catalysis on Zeolites. Acc. Chem. Res. 41, 559-567 (2008).

3. Yarulina I, Chowdhury AD, Meirer F, Weckhuysen BM, Gascon J. Recent trends and fundamental insights in the methanol-to-hydrocarbons process. Nat. Catal. 1, 398-411 (2018).

4. Olsbye U, et al. Conversion of Methanol to Hydrocarbons: How Zeolite Cavity and Pore Size Controls Product Selectivity. Angew. Chem. Int. Edit. 51, 5810-5831 (2012).

5. Ilias S, Bhan A. Mechanism of the Catalytic Conversion of Methanol to Hydrocarbons. ACS Catal. 3, 18-31 (2013).

6. Yarulina I, et al. Structure-performance descriptors and the role of Lewis acidity in the methanol-topropylene process. Nat. Chem. 10, 804-812 (2018).

7. Bailleul S, et al. A Supramolecular View on the Cooperative Role of Brønsted and Lewis Acid Sites in Zeolites for Methanol Conversion. J. Am. Chem. Soc. 141, 14823-14842 (2019).

8. Wang $\mathrm{H}$, et al. Insight into the Effects of Water on the Ethene to Aromatics Reaction with HZSM-5. ACS Catal. 10, 5288-5298 (2020).

9. Li C, Paris C, Martínez-Triguero J, Boronat M, Moliner M, Corma A. Synthesis of reaction-adapted zeolites as methanol-to-olefins catalysts with mimics of reaction intermediates as organic structuredirecting agents. Nat. Catal. 1, 547-554 (2018).

10. Wang $S$, et al. Relation of Catalytic Performance to the Aluminum Siting of Acidic Zeolites in the Conversion of Methanol to Olefins, Viewed via a Comparison between ZSM-5 and ZSM-11. ACS Catal. 8, 5485-5505 (2018).

11. Ravi M, Sushkevich VL, van Bokhoven JA. Towards a better understanding of Lewis acidic aluminium in zeolites. Nat. Mater. 19, 1047-1056 (2020).

12. Brus J, et al. Structure of Framework Aluminum Lewis Sites and Perturbed Aluminum Atoms in Zeolites as Determined by 27AI $\{1 \mathrm{H}\}$ REDOR (3Q) MAS NMR Spectroscopy and DFT/Molecular Mechanics. Angew. Chem. Int. Edit. 54, 541-545 (2015). 
13. Klinowski J, Fyfe CA, Gobbi GC. High-resolution solid-state nuclear magnetic resonance studies of dealuminated zeolite Y. J. Chem. Soc. Faraday Trans. 1 81, 3003-3019 (1985).

14. Bevilacqua M, Busca G. A study of the localization and accessibility of Brønsted and Lewis acid sites of H-mordenite through the FT-IR spectroscopy of adsorbed branched nitriles. Catal. Commun. 3, 497502 (2002).

15. Marques JP, et al. Infrared spectroscopic study of the acid properties of dealuminated BEA zeolites. Microporous Mesoporous Mater. 60, 251-262 (2003).

16. Yu Z, et al. Insights into the Dealumination of Zeolite HY Revealed by Sensitivity-Enhanced 27AI DQMAS NMR Spectroscopy at High Field. Angew. Chem. Int. Edit. 49, 8657-8661 (2010).

17. Wang $\mathrm{N}$, et al. Modulation of b-axis thickness within MFI zeolite: Correlation with variation of product diffusion and coke distribution in the methanol-to-hydrocarbons conversion. Appl. Catal. B: Environ. 243, 721-733 (2019).

18. Shen K, Qian W, Wang N, Su C, Wei F. Fabrication of c-Axis Oriented ZSM-5 Hollow Fibers Based on an in Situ Solid-Solid Transformation Mechanism. J. Am. Chem. Soc. 135, 15322-15325 (2013).

19. Zhang J, Qian W, Kong C, Wei F. Increasing para-Xylene Selectivity in Making Aromatics from Methanol with a Surface-Modified Zn/P/ZSM-5 Catalyst. ACS Catal. 5, 2982-2988 (2015).

20. Stöcker M. Methanol-to-hydrocarbons: catalytic materials and their behavior1Dedicated to my wife Wencke Ophaug.1. Microporous Mesoporous Mater. 29, 3-48 (1999).

21. Liu $\mathrm{H}$, et al. The effects of carbonaceous species in HZSM-5 on methanol-to-olefin process. Appl. Catal. A Gen. 421-422, 108-113 (2012).

22. Hay DG, Jaeger H, Wilshier KG. Systematic intergrowth in crystals of ZSM-5 zeolite. Zeolites 10, 571576 (1990).

23. Stavitski E, Drury MR, de Winter DAM, Kox MHF, Weckhuysen BM. Intergrowth Structure of Zeolite Crystals and Pore Orientation of Individual Subunits Revealed by Electron Backscatter Diffraction/Focused Ion Beam Experiments. Angew. Chem. Int. Edit. 47, 5637-5640 (2008).

24. Karwacki L, et al. Morphology-dependent zeolite intergrowth structures leading to distinct internal and outer-surface molecular diffusion barriers. Nat. Mater. 8, 959-965 (2009).

25. Price GD, Pluth JJ, Smith JV, Bennett JM, Patton RL. Crystal structure of tetrapropylammonium fluoride-containing precursor to fluoride silicalite. J. Am. Chem. Soc. 104, 5971-5977 (1982).

26. Wang $\mathrm{C}$, et al. Maximizing sinusoidal channels of HZSM-5 for high shape-selectivity to $\mathrm{p}$-xylene. Nat. Commun. 10, 4348 (2019).

27. Chen Q, et al. Imaging Beam-Sensitive Materials by Electron Microscopy. Adv. Mater. 32, 1907619 (2020).

28. Baerlocher C, et al. Structure of the Polycrystalline Zeolite Catalyst IM-5 Solved by Enhanced Charge Flipping. Science 315, 1113 (2007).

29. Willhammar T, et al. Structure and catalytic properties of the most complex intergrown zeolite ITQ-39 determined by electron crystallography. Nat. Chem. 4, 188-194 (2012). 
30. Smeets S, et al. High-Silica Zeolite SSZ-61 with Dumbbell-Shaped Extra-Large-Pore Channels. Angew. Chem. Int. Edit. 53, 10398-10402 (2014).

31. Shen B, et al. Atomic Spatial and Temporal Imaging of Local Structures and Light Elements inside Zeolite Frameworks. Adv. Mater. 32, 1906103 (2020).

32. Shen B, Chen X, Shen K, Xiong H, Wei F. Imaging the node-linker coordination in the bulk and local structures of metal-organic frameworks. Nat. Commun. 11, 2692 (2020).

33. Flanigen EM, et al. Silicalite, a new hydrophobic crystalline silica molecular sieve. Nature 271, 512516 (1978).

34. Kokotailo GT, Lawton SL, Olson DH, Meier WM. Structure of synthetic zeolite ZSM-5. Nature 272, 437438 (1978).

35. Olson DH, Kokotailo GT, Lawton SL, Meier WM. Crystal structure and structure-related properties of ZSM-5. J. Phys. Chem. 85, 2238-2243 (1981).

36. Emeis CA. Determination of Integrated Molar Extinction Coefficients for Infrared Absorption Bands of Pyridine Adsorbed on Solid Acid Catalysts. J. Catal. 141, 347-354 (1993).

37. Maache M, Janin A, Lavalley JC, Joly JF, Benazzi E. Acidity of zeolites Beta dealuminated by acid leaching: An FTi.r. study using different probe molecules (pyridine, carbon monoxide). Zeolites 13, 419-426 (1993).

38. Ravi M, Sushkevich VL, van Bokhoven JA. Lewis Acidity Inherent to the Framework of Zeolite Mordenite. J. Phys. Chem. C 123, 15139-15144 (2019).

39. O'Dell LA, Savin SLP, Chadwick AV, Smith ME. A 27AI MAS NMR study of a sol-gel produced alumina: Identification of the NMR parameters of the $\theta$-Al203 transition alumina phase. Solid. State. Nucl. Mag. 31, 169-173 (2007).

40. Bjørgen M, Joensen F, Lillerud K-P, Olsbye U, Svelle S. The mechanisms of ethene and propene formation from methanol over high silica H-ZSM-5 and H-beta. Catalysis Today 142, 90-97 (2009).

41. Sun $X$, et al. On reaction pathways in the conversion of methanol to hydrocarbons on HZSM-5. J. Catal. 317, 185-197 (2014).

42. Wang S, et al. Polymethylbenzene or Alkene Cycle? Theoretical Study on Their Contribution to the Process of Methanol to Olefins over H-ZSM-5 Zeolite. J. Phys. Chem. C119, 28482-28498 (2015).

\section{Figures}



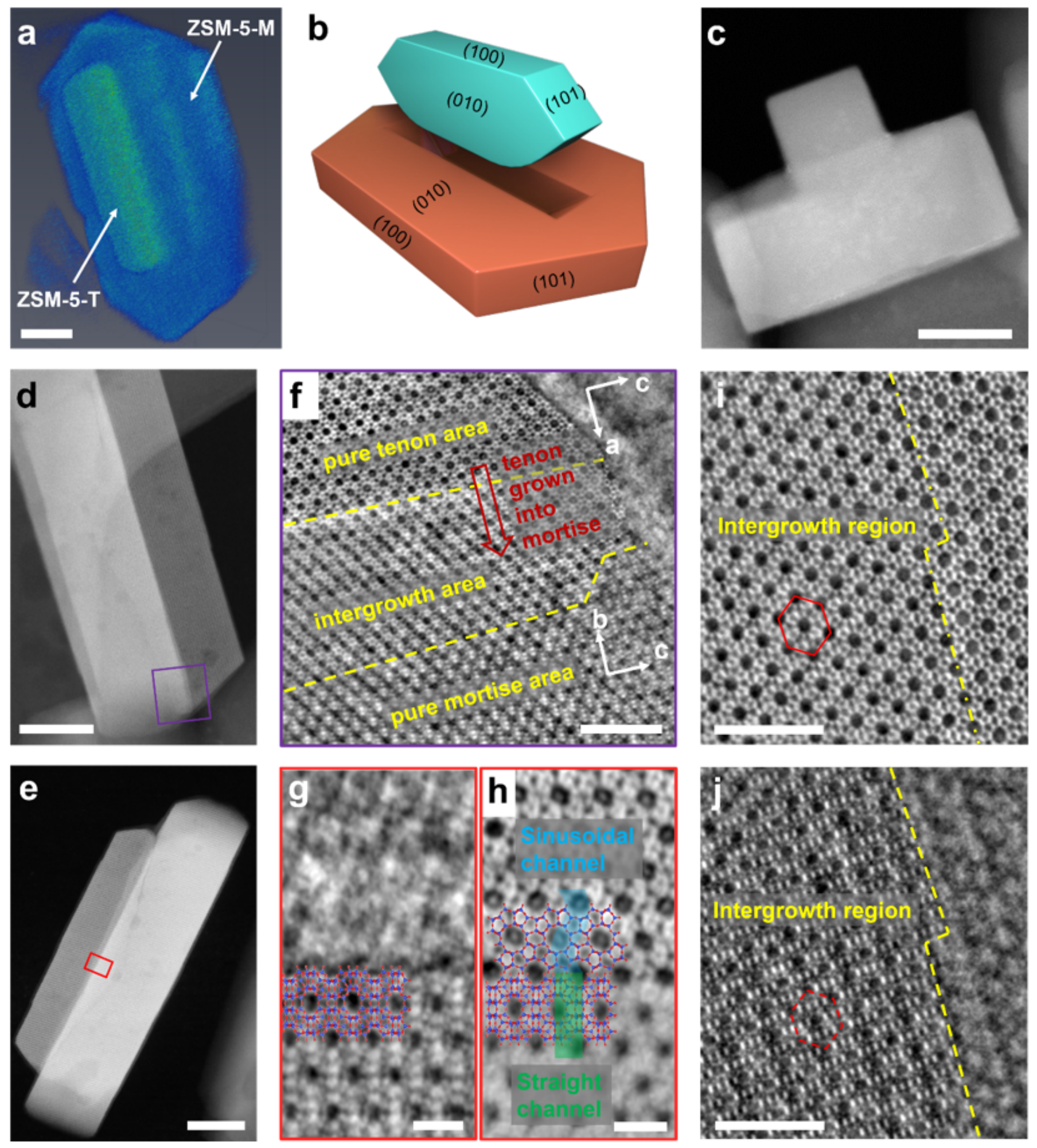

\section{Figure 1}

Revealing morphology of ZSM-5-MT catalyst. a, 3D electron tomographic reconstruction of individual ZSM-5-MT nanocrystal. b, Schematic model of ZSM-5-MT nanocrystal with tenon and mortise subunit. c, ADF-STEM image of ZSM-5-MT from the [001] projection. d-h, ADF- and iDPC-STEM images revealing the intergrowth structures in ZSM-5-MT from the lateral projection. It is shown that the mortise and tenon grow into each other with perfect connection of different types of channels. i and j, Imaging the straight 
channels in mortise and the sinusoidal channels in tenon at the same area by the iDPC-STEM imaging with different defocuses. Scale bars, $50 \mathrm{~nm}$ in a and c-e, $5 \mathrm{~nm}$ in f, i, and j, $2 \mathrm{~nm}$ in $\mathrm{g}$ and h.
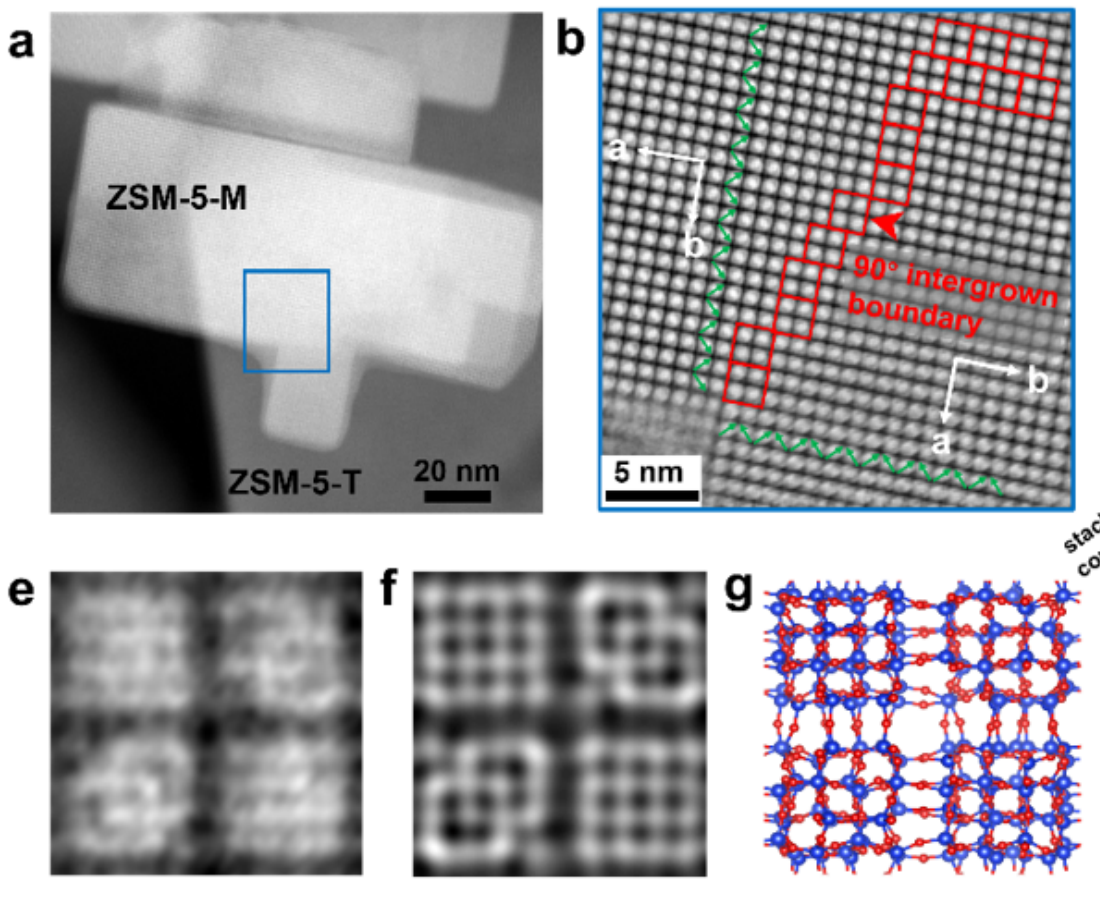
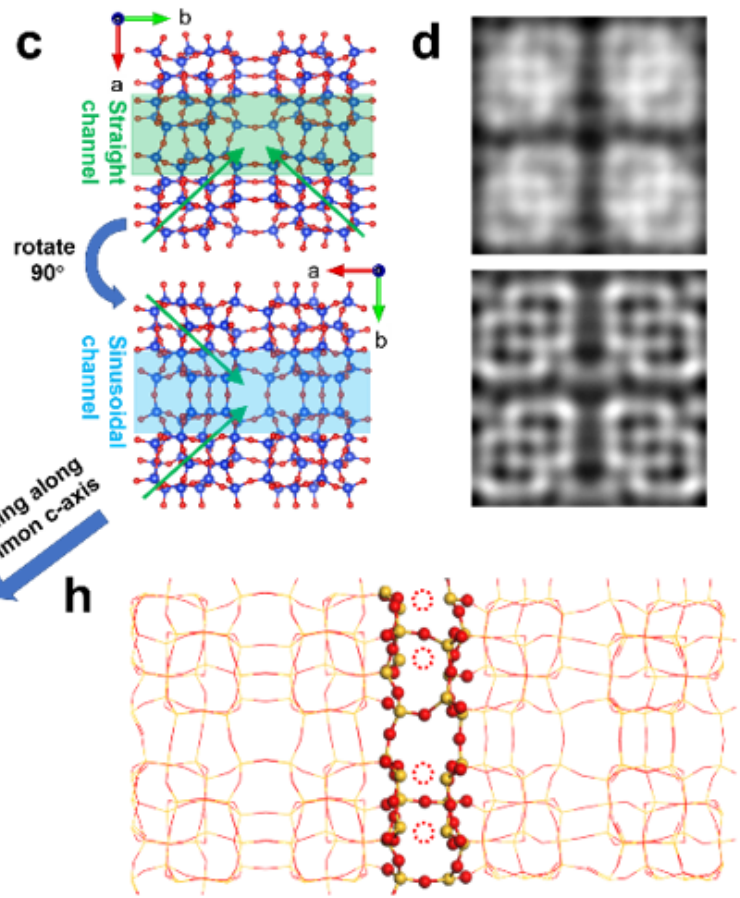
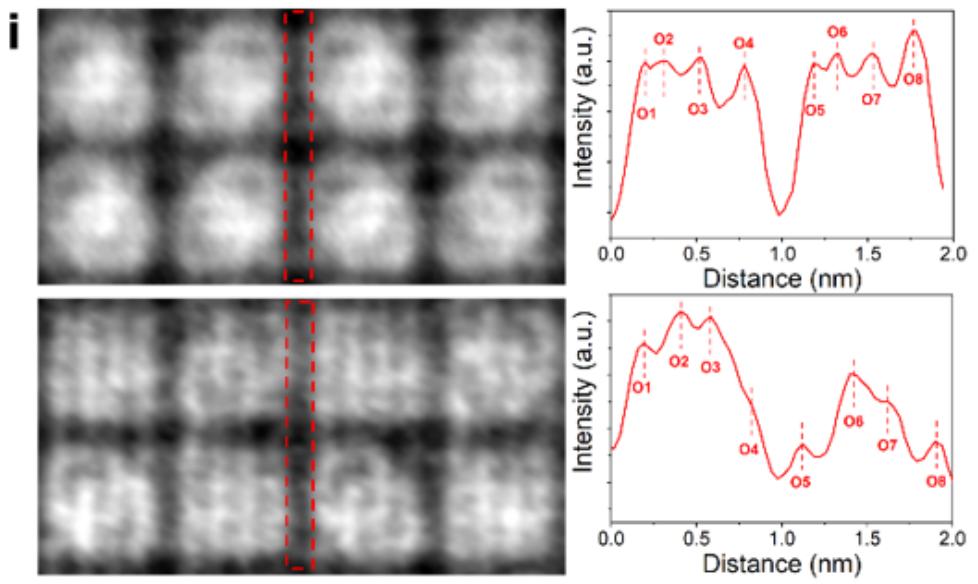

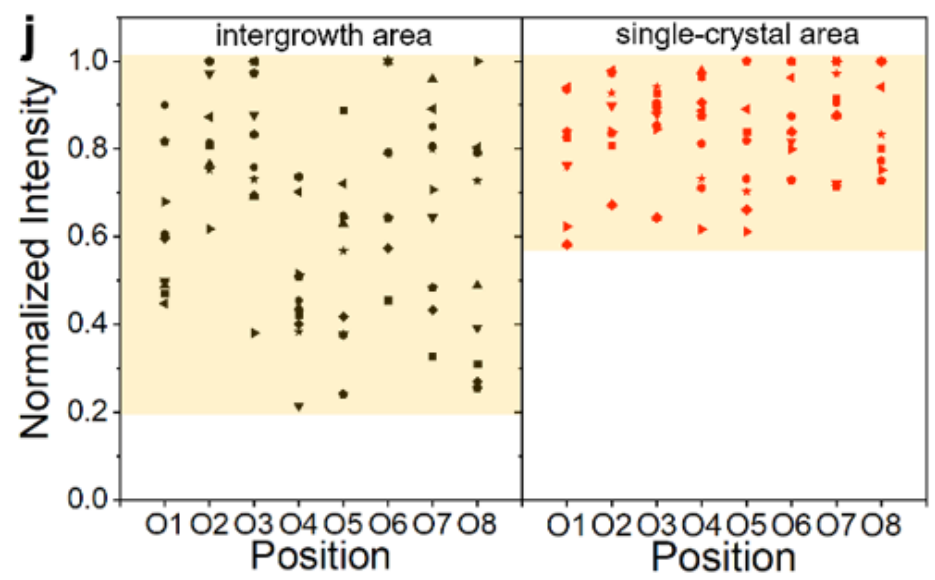

Figure 2

Atomic interface structures in ZSM-5-MT catalyst. a, ADF-STEM image of ZSM-5-MT from the [001] projection. $b$, Magnified iDPC-STEM image of intergrowth interface in the area marked by the blue frame in a. The intergrowth area between mortise and tenon is marked by red frames. c, Structural models of ZSM-5 from the [001] projection. d, Magnified iDPC-STEM image (top) and simulated projected electrostatic potential of ZSM-5 lattice in pure mortise or tenon area (bottom) from the [001] projection. e$\mathrm{g}$, Magnified iDPC-STEM image, simulated projected electrostatic potential and structural model of overlapped lattices in the intergrowth area by stacking two models in c along c-axis of ZSM-5. h, Structural model of the interface in ZSM-5-MT showing the partial missing of 0 atoms due to the slight lattice mismatch. i, Magnified iDPC-STEM images of single-crystal (top) and intergrowth (bottom) areas from the [001] projection and corresponding intensity profiles. Eight positions and intensities of eight 0 atom columns can be identified in each profile. j, Statistical results of the normalized intensities of 0 
peaks in single-crystal (red symbol) and intergrowth (black symbol) areas. In statistics, 10 data are included for each area and different shapes of symbol are corresponding to the data in different profiles (Supplementary Fig. 6-9).
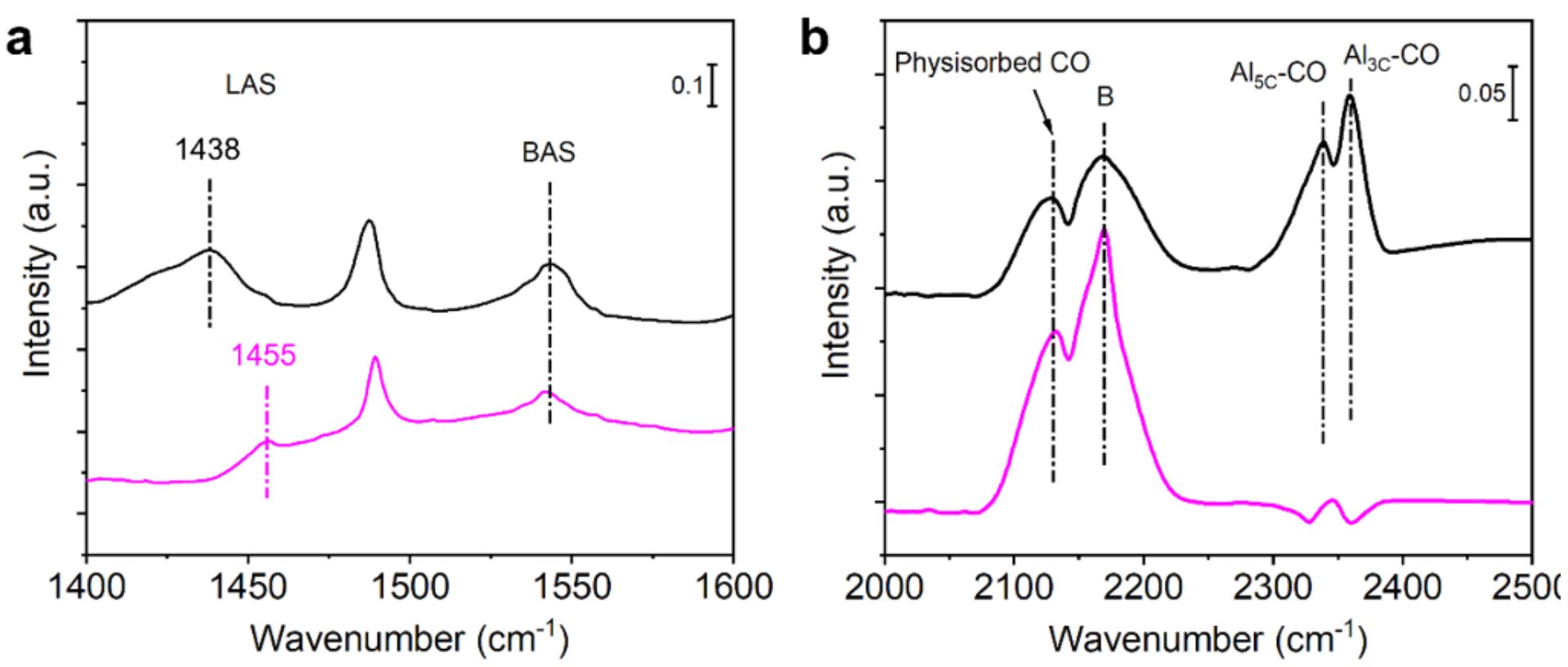

C

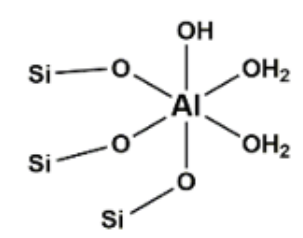

hydrated framework-associated aluminum

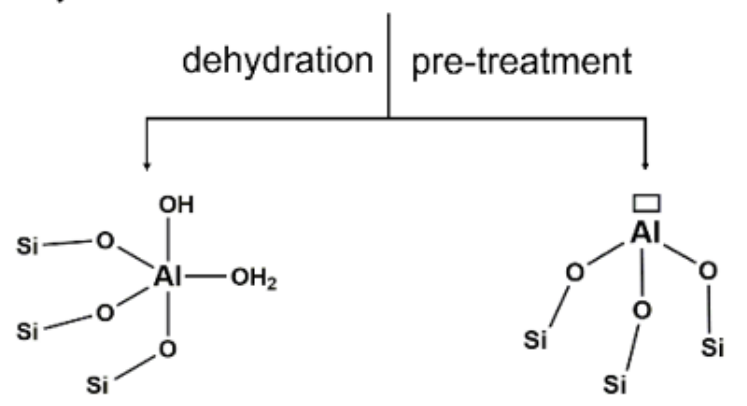

penta-coordinated aluminum tri-coordinated aluminum

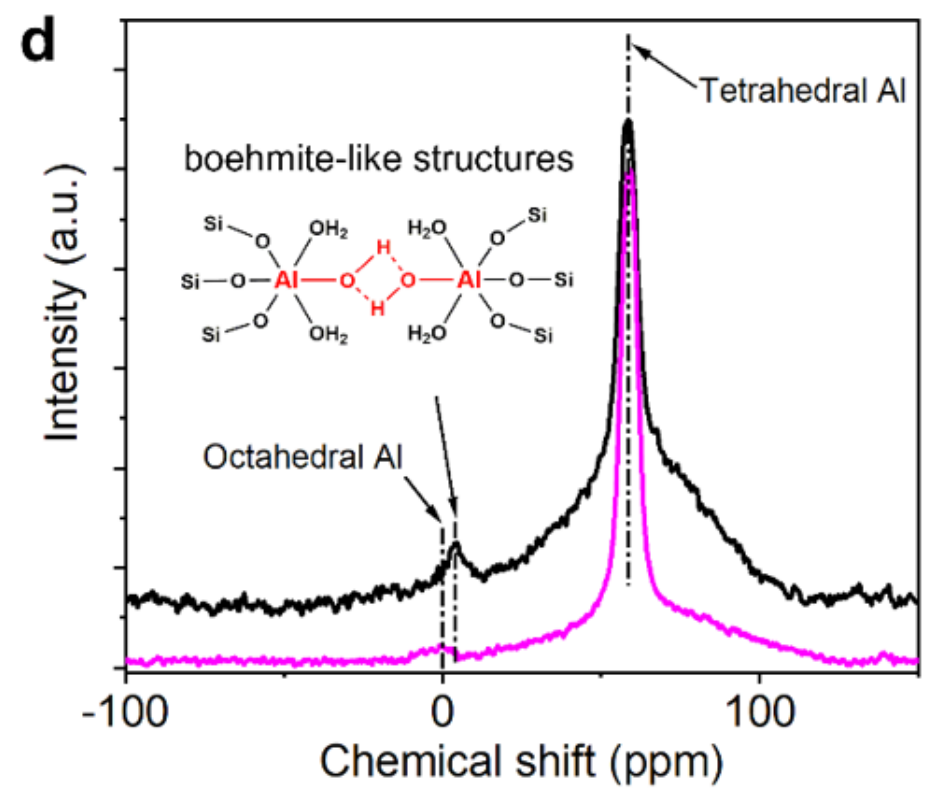

Figure 3

Lewis acidity in ZSM-5-MT catalyst. a, FTIR spectroscopy of adsorbed pyridine in ZSM-5-MT (black line) and ZSM-5-Sb (pink line). L/B represents the concentration ratio of LAS/BAS. b, FTIR spectroscopy of adsorbed CO in ZSM-5-MT (black line) and ZSM-5-Sb (pink line). c, Structural evolution of tri-coordinated AlFR LASs under different conditions. d, 27AI MAS NMR of ZSM-5-MT (black line) and ZSM-5-Sb (pink line). 

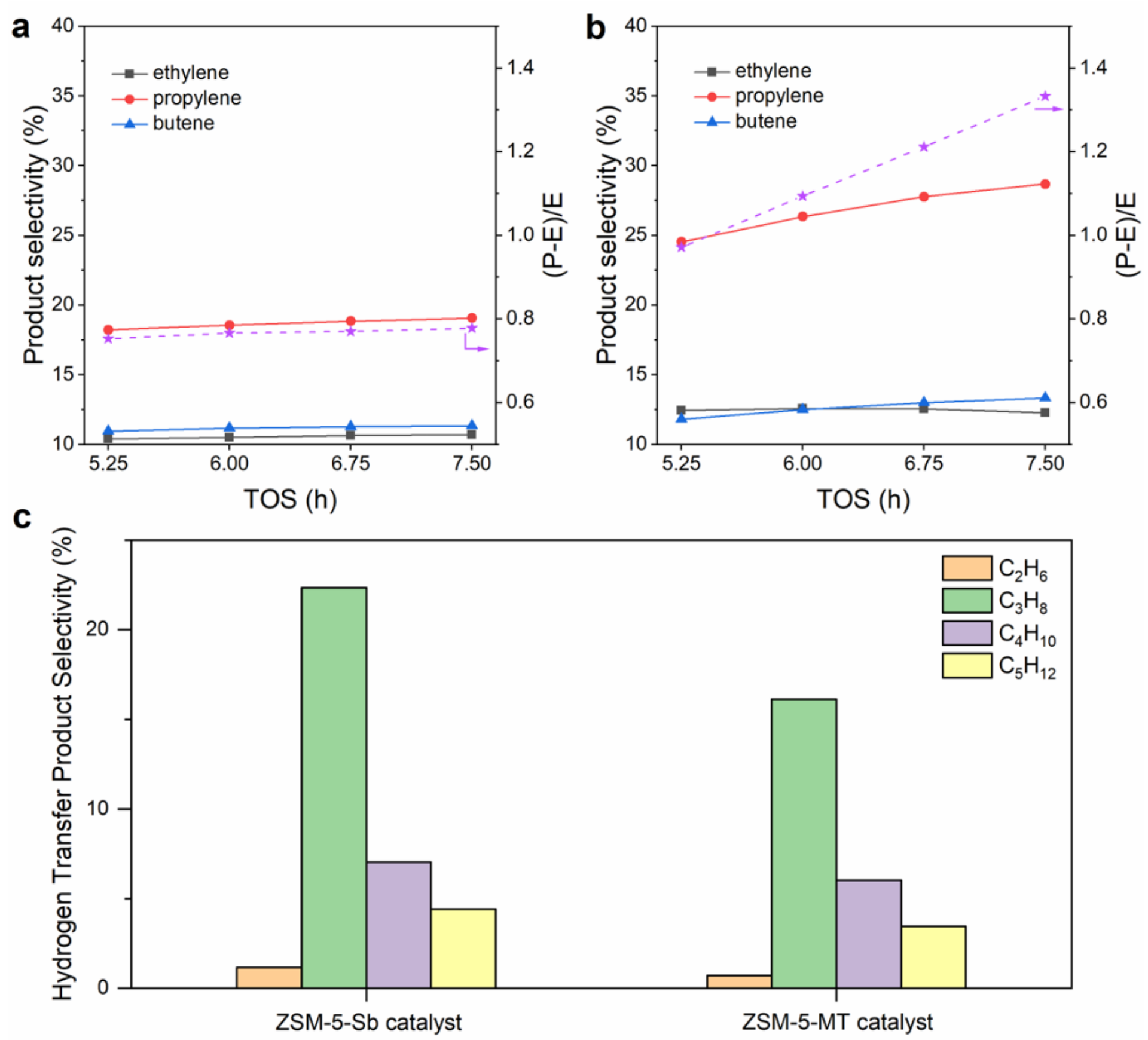

Figure 4

Catalytic performance of ZSM-5-MT catalyst. a and b, Selectivity of light olefins (ethylene, propylene and butene) and the (P-E)/E ratio for MTH over ZSM-5-Sb (a) and ZSM-5-MT (b) catalysts. Test conditions: complete methanol conversion ( $\geq 99 \%$ ), $475{ }^{\circ} \mathrm{C}$, weight hourly space velocity (WHSV) of $5 \mathrm{~h}-1$ ). c, Selectivity of alkanes in the propylene conversion over ZSM-5-Sb and ZSM-5-MT catalysts. Test conditions: complete propylene conversion ( 95\%), $450{ }^{\circ} \mathrm{C}$, weight hourly space velocity (WHSV) of $3 \mathrm{~h}-$ 1).

\section{Supplementary Files}


This is a list of supplementary files associated with this preprint. Click to download.

- 0c43dc7a6628e4d3dc5b355a5c40f9f0.mp4

- SImanuscriptsMortiseTenonZeolites0323.docx 